\title{
POR UMA REFLEXÃO ÉTICA DO DIAGNÓSTICO PRECOCE EM PRÁTICAS COMPLEMENTARES
}

\section{FOR AN ETHICAL REFLECTION ABOUT EARLY DIAGNOSIS IN COMPLEMENTARY PRACTICES}

Prevenir é melhor que remediar! O ditado é antigo. Representa um produto histórico da sociedade brasileira inscrito no senso comum como uma recomendação normativa que exige mudanças de hábitos e atitudes, visando à antecipação da possibilidade de adoecer. Mediado e arquitetado pelo conhecimento científico, tem origem em um modelo teórico explicativo do processo saúde-doença, criado na década de 1930 nos Estados Unidos, materializado nos anos 60, e hegemonizado em países afins após a Segunda Guerra Mundial, dentre estes, o Brasil: o modelo da história natural da doença.

Esse fundamento teórico instituiu o preventivismo epistemológico, em uma fase da doença denominada pré-patogênica, que, em última análise, representa um estilo de pensamento ${ }^{1}$ que circulava nas relações sociais, culturais e políticas daquela época. Tal estilo legitimou o ditado, que se apresenta pulsante no contemporâneo e revigorado pelo discurso do risco e da hiperprevenção. Risco e hiperprevenção: duas construções sociais indutoras da sociedade do medo, destinadas à produção de subjetividades que parecem gerar mais doenças do que impulsionar a saúde.

A moda atual é galgar prevenção pela medicina personalizada, campo do conhecimento que busca especificidades da individualidade pessoal para diagnóstico e tratamento. As possibilidades na área biomédica vão desde testes genéticos ao banco de sangue do cordão umbilical para produzir terapias farmacogenéticas. A medicina preditiva, dimensão da medicina personalizada, pretende fazer predições sobre o desenvolvimento de enfermidades de bases genéticas no futuro. Embora essas tecnologias possam ter potencial no arsenal de cuidados à saúde, elas também implicam questões éticas, ${ }^{2}$ cabendo citar a reprodução da iniquidade de acesso à atenção à saúde, uma vez que apenas uma pequena parcela da população brasileira tem recursos materiais para garantir "medicina personalizada".

Nas relações de produção da medicina personalizada e preditiva estão presentes práticas integrativas e/ou complementares , mas a aproximação não se dá no âmbito das questões técnicas, mas naquilo que elas pretendem ou prometem. Isto é, no conteúdo velado. Tal como a medicina personalizada, a maioria das práticas integrativas e complementares baseiam-se numa abordagem individual. E algumas dessas práticas são métodos de avaliação que, em certas situações, pretendem prever adoecimentos futuros.

Não é difícil encontrar entre os profissionais que lançam mão de práticas não-convencionais em saúde aqueles que afirmam utilizar de técnicas que podem prever antecipadamente doenças, localizadas no "campo energético" e que ainda não afetaram o "corpo físico". Também no meio científico, algumas estudos de terapias complementares conduzem para um possível diagnóstico bastante antecipado. Para fins desse Editorial, elencamos o método da bioeletrografia (foto kirlian). Contudo, essas reflexões aplicam-se ainda no caso da radiestesia em saúde, da iridologia, e de outras formas preditivas do campo da saúde. 
Em uma revisão sistemática sobre o método GDV (GasDischargeVisualization), nome dado ao modelo russo de bioeletrografiai, os autores afirmam que o método permite avaliação precoce da probabilidade de câncer em potencial ${ }^{3}$. A revisão mostra que os estudos sobre a técnica GVD focam no diagnóstico e prognóstico precoce de estados pré-clínicos, indicando que o método GDV é mais informativo do que os métodos de diagnóstico clínico-tradicionais ${ }^{3}$. Contudo, faz-se oportuno contextualizar o fato de o autor principal dessa revisão sistemática, que anuncia a promessa do diagnóstico precoce de câncer, ser o desenvolvedor da técnica GVD e único comerciante do método.

Vale lembrar que, até o presente momento, nenhuma pesquisa consegue realmente comprovar com clareza que tais avaliações (não apenas a bioeletrografia, mas iridologia, radiestesia, entre outras) realmente diagnosticam precocemente. E se assim o fizessem, como seria possível creditar o diagnóstico precoce de distúrbios orgânicos à técnica, em meio às possibilidades (reais) de o adoecimento ter sido decorrente de questões geradas na determinação social do processo saúde-doença, onde condições de vida, modelo de organização social e dimensão psicológica respondem pela causação?

Ivan Illich, já na década de 1970, denunciava as consequências iatrogênicas derivadas das intervenções médicas para diagnóstico precoce ${ }^{4}$. Dizia ele que a manutenção dos corpos, através de cuidados preventivos, era uma forma de consumismo que transformava pessoas que se sentiam bem em pacientes ansiosos. Ilich alertava que a medicalização da prevenção, sobretudo para aquelas doenças cujos tratamentos não são tão eficazes, como certos casos de cânceres, era um artifício para rejeitar o fracasso dos tratamentos para tais doenças (na medida em que se dizia que era preciso diagnosticar precocemente para ter mais chances da eficácia do tratamento), além de ser uma estratégia para incremento clientelista ${ }^{4}$.

A Bioeletrografia, bem como outros métodos complementares, tem potencial para ser um método não-invasivo, não doloroso e contribuir para o cuidado da saúde humana. Entretanto, não apenas mais pesquisas são necessárias, mas, sobretudo, reflexões e análises éticas que problematizem as implicações de tais técnicas na práxis terapêutica.

Por fim, considera-se a utilização de tais métodos avaliativos preditivos como, dependendo da maneira que são conduzidos, instrumentos para a coisificação de sujeitos, no sentido de induzir o sujeito consultante a comportar-se como objeto do profissional, que passaa ser o responsável pela mensuração do estado de saúde do sujeito. Desse modo, a autonomia, que genuinamente deveria ser construída na relação saudável de interdependência entre o consultante e o profissional, no domínio da liberdade ${ }^{5}$, é deslocada para a submissão do primeiro ao segundo, transformando-o em verdadeiro "paciente", sempre com voz passiva, e cada vez mais distante da possibilidade de alcançar o status de "interagente": aquele que interage e tem voz ativa nos seus processos de saúde/adoecimento, tal como discursa a Naturologia (embora o discurso não necessariamente represente a prática).

Nesse sentido, as avaliações profiláticas, no campo das práticas integrativas e complementares, também não são isentas de implicações éticas. A minimização da autonomia dos "pacientes", a partir de recursos sedutores e persuasivos, e os prováveis efeitos iatrogênicos, resultantes de avaliações precoces com finalidades preventivas, estão entre as implicações que podem ocorrer.

Faz-se categórico, portanto, atentar para o conflito de interesses, presente em pesquisas na área das técnicas preditivas e para os vazios de problematização ética, histórica e social no desenvolvimento desse tipo de conhecimento científico. Faz-se necessário reconhecer os efeitos deletérios gerados na produção cotidiana da vida, sobretudo psicológicos e sociais, pelas afirmações de detecção precoce de câncer - para as quais nem sempre

i Bioeletrografia (foto kirlian) é uma técnica utilizada para análise do estado de saúde através das fotografias das polpas dos dedos. Um gerador de corrente elétrica pulsante, de alta tensão, alta frequência e baixa corrente, fornece uma descarga elétrica à uma placa metálica isolante e cria nesta um campo eletromagnético. Ao ser colocado a polpa do dedo (ou outro objeto), a chapa fotográfica registra o efeito luminescente conhecido como efeito corona. $\mathrm{O}$ registro deste efeito elétrico é utilizado para análise. 
existem métodos eficazes. Importante se faz também reconhecer os artifícios persuasivos do consumismo e modismo que operam no campo da saúde. Na mesma medida, a necessidade de formação de profissionais em saúde pautada em pedagogias reflexivas, questionadoras que problematizem a condição humana e os efeitos de construções sociais produzidas pela ciência. Por fim, que as práticas diagnósticas não convencionais em saúde sejam tratadas e socializadas pelos seus agentes com parcimônia e que seus limites sejam divulgados.

\section{Fernando Hellmann}

Editor-adjunto

\section{Rita de Cássia Gabrielli Souza Lima}

Doutora em Saúde Coletiva pela Universidade Federal de Santa Catarina, com Estágio de Doutorado (Sanduíche - CAPES) na Università Degli Studi di Roma 'La Sapienza' - Itália. Mestre em Saúde Pública

\section{REFERÊNCIAS}

1. Fleck L. Gênese e Desenvolvimento de um Fato Científico. Belo Horizonte: Fabrefactum; 2010.

2. Astoni Júnior IMB, Ianotti GC. Ética e medicina preditiva. Rev. Bras. Saude Mater. Infant., Recife , v. 10, supl. 2, Dec. 2010. http://dx.doi.org/10.1590/ S1519-38292010000600016.

3. Korotkov KG, Matravers P, Orlov DV, Williams BO. Application of electrophotoncapture (EPC) analysis based on gas discharge visualization (GDV) technique in medicine: a systematic review. J AlternComplement Med. 2010 Jan;16(1):13-25. doi: 10.1089/acm.2008.0285.

4. Illich I. A expropriação da saúde; nêmesis da medicina. Rio de Janeiro: Nova Fronteira; 1975.

5. Canguilhem G. O Normal e o Patológico. São Paulo: Forense Universitária; 2006. 